\begin{tabular}{|c|c|c|}
\hline$A$ & $\begin{array}{c}\text { International Journal of Current Research } \\
\text { and Academic Review }\end{array}$ & \\
\hline $\begin{array}{l}\text { EXCELLENT } \\
\text { PUBLISHERS }\end{array}$ & $\begin{array}{c}\text { ISSN: 2347-3215 (Online) } \because, \text { Volume } 5:, ; \text { Number } 4 \text { (April-2017) } \\
\text { Journal homepage: http://www.ijcrar.com }\end{array}$ & \\
\hline
\end{tabular}

doi: https://doi.org/10.20546/ijcrar.2017.504.003

\title{
Assessment of Knowledge Regarding Essential New Born Care among Women Availing Antenatal Care Services at a Rural Maternity Hospital in Southern Karnataka, India
}

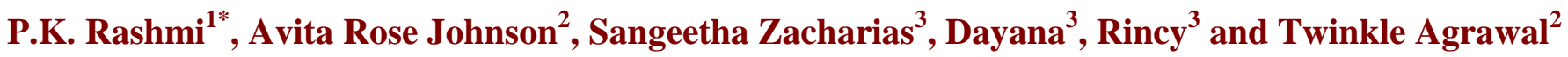 \\ ${ }^{1}$ Post graduate student, ${ }^{2}$ Assistant Professor, ${ }^{3}$ Medical Intern, Department of Community Health, St. John's Medical \\ College, Bangalore, India
}

*Corresponding author

\begin{abstract}
Every year 4 million babies die in the first month of life and a quarter of these takes place in India. Essential new born care and proper breastfeeding practices have a proven impact on reducing the infant mortality rate. This study was conducted with the aim to assess the knowledge regarding essential new born care among women availing antenatal services. A cross - sectional study was conducted among women availing antenatal care services at a maternity hospital in a rural area of South Karnataka. A face-validated structured interview was administered to 201 women and data were analyzed. There was overall poor knowledge regarding essential newborn care and breastfeeding practices among women in the area of study. As the parity of the women increased, they scored better in the newborn care and the breastfeeding questionnaire. Conclusion and recommendation: The knowledge and access to knowledge among rural women regarding newborn care practices and breastfeeding was poor. Health education regarding newborn care practices should be imparted to new mothers, relatives and adolescent girls because adequate knowledge among mothers is the first step to the practice of good breastfeeding and essential new born care.
\end{abstract}

\section{Article Info}

Accepted: 28 March 2017

Available Online: 20 April 2017

\section{Keywords}

Essential newborn care, breastfeeding, knowledge, antenatal women, cross-sectional.

\section{Introduction}

'The moment a child is born, a mother also is born' says a famous Indian quote. This is true in all parts of the world where motherhood is welcomed with delight, expectation and also nervousness. However, motherhood also comes with a certain set of responsibilities; which when practiced is beneficial to both the mother and the baby. For this, a good knowledge regarding breastfeeding and newborn care practices are essential for any woman.
India, as we know, is a developing country. Our country has focused a significant amount of time and energy for the reduction of maternal mortality and child mortality. Yet, the figures are grim. The recent data obtained from NFHS-4(2017) states that the infant mortality rates in India are 41 per 1000 live births. The most common cause of infant mortality in India is pneumonia, which can be easily prevented by good breastfeeding practices along with a basic newborn care to the women. 
Some of the major factors that affect exclusivity and duration of breastfeeding include breast problems such as sore nipples or mother's perceptions that she is producing inadequate milk, inadequate breastfeeding knowledge; lack of familial and societal support; lack of guidance and encouragement from health care professionals according to Cherop et al., (2011), Nkala et al., (2009) and Thurman et al., (2008)

$\mathrm{WHO}(2017)$ states that very year 4 million babies die in the first month of life and a quarter of these takes place in India. Essential new born care and proper breastfeeding practices have a proven impact on reducing the infant mortality rate. Evidence-based practices like skin-to -skin contact, keeping the baby warm, care of the umbilical cord and exclusive breastfeeding should be promoted, as these are life-saving measures for the newborn(WHO Guidelines).However, data shows that only $25 \%$ babies were breastfed within $1 \mathrm{hr}$, only $43 \%$ did not receive pre-lacteal feed, and only $46 \%$ babies were exclusively breastfed for 6 months(NFHS-4). Adequate knowledge among mothers is the first step to the practice of good breastfeeding and essential new born care.It is important that the right information is provided to mothers during the antenatal period itself so that correct evidence -based practices in the care of the newborn will be followed immediately after delivery, and continued into the post partum period. Therefore, this study was conducted with the aim to assess the knowledge regarding essential new born care among women availing antenatal services at Snehalaya hospital, Solur.

\section{Methodology}

A cross - sectional study was conducted among women availing antenatal care services at a maternity hospital in a rural area of Ramnagara district in South Karnataka. The sample size was calculated to be 90 .All pregnant women who attended the hospital over a two month period were included in the study. A face-validated structured interview was administered, consisting of sociodemographic details, knowledge regarding breastfeeding practices and newborn care practices.

The questionnaire administered consisted of four parts. The first part consisted of Sociodemographic details, second part regarding marital history and past obstetric history, the third part consisted of knowledge and attitude of the women towards breastfeeding, and the fourth part consisted of questions regarding essential newborn care.
In the third section, i.e., the knowledge and attitude towards breastfeeding, women were asked questions regarding frequency of breastfeeding, colostrum, prelacteal feeding and benefits of breastfeeding. The highest score was 24 . In the fourth section, questions were asked based on the guidelines of essential newborn care; regarding cord care, vaccination, thermoregulation and physiological signs in a newborn. The highest possible score here was 10 . Women who were in labour or unable to comprehend the questions were excluded from the study. Written informed consent was obtained from the study participants and the study was granted approval from the Institution Ethics Committee.

Data was entered in Microsoft Excel and analyzed using SPSS V.16. Socio-demographic data and obstetric data were described by mean and standard deviation. Student's t test and ANOVA test were used to look for association between knowledge scores of breastfeeding and essential newborn care and the various sociodemographic and obstetric variables. A p value of $<0.05$ was considered to be significant.

\section{Results and Discussion}

\section{Socio demographic details}

This study considered a total of 201 antenatal women. Most of the women belonged to the age group of 19-25 years $(76.1 \%)$, with the mean age of the population being $22.45+2.58$ years. Most of the women belonged to Hindu religion (93.5\%) and hailed from a joint or three generation family (80.6\%). Majority had attained education up to the level of high school (81.1\%). In the study population, the average per capita income was Rs. $3485.93+4417.50$.

\section{Knowledge regarding breastfeeding in the study population}

On administering the questionnaire to the study population about knowledge regarding breastfeeding in the population, it was found that majority of the population was majorly lacking in the knowledge regarding the breastfeeding of a newborn. Mean score for knowledge regarding breastfeeding was 8.57 out of a maximum score of 24 .

Only around one-third of the women exhibited awareness regarding the importance of keeping the baby warm while breastfeeding and answered positively regarding the feeding of colostrum. Most women did not know the 
quantity of milk produced in the first day. Disappointingly, $90 \%$ of the women believed that sugar/ jaggery/ ghee should be given to the baby as soon as the baby is born.

\section{Knowledge regarding new born care practices in the study population}

The mean score for knowledge regarding essential newborn care was 3.7 out of a highest possible score of 10. Most of the women (53.2\%) agreed with the interviewers saying BCG vaccine should be given soon after birth. However, most of the women did not possess knowledge regarding when the baby should pass stools for the first time. Only $14.4 \%$ of the women interviewed answered the question correctly.

There was a significant association between parity and the scoring in the individuals. As the parity of the women increased, they scored better in the newborn care and the breastfeeding questionnaire.

A total of 201 women residing in rural areas were considered for this study. Most were young women, pregnant for the first time.

In spite of the law (Prohibition of child marriage Act, 2006), against child marriage according to the constitution, at least 8 women interviewed were underage (below 18 years of age). There could have been an underreporting of child marriages owing to legal repercussions. This is a worrying statistic, as teenagers have low knowledge regarding breastfeeding and newborn care practices, along with the dangers of teenage pregnancy and ill effects of it on them and their baby AS found by Madhu et al., (2009). We found this in the present study, however this was not statistically significant.

Table.1 Description of the study population

\begin{tabular}{|l|l|l|}
\hline $\begin{array}{l}\text { Sociodemographic } \\
\text { factors }\end{array}$ & Categories & Frequency (Percentage) \\
\hline Age & $<18$ years & $20(10 \%)$ \\
& $19-25$ years & $153(76.1 \%)$ \\
& $>26$ years & $28(13.9 \%)$ \\
\hline Religion & Hindu & $188(93.5 \%)$ \\
& Muslim & $13(6.5 \%)$ \\
\hline Type of family & Nuclear & $39(19.4 \%)$ \\
& Joint or Three generation & $162(80.6 \%)$ \\
\hline Education & Illiterate & $1(0.5 \%)$ \\
& Primary School & $12(6 \%)$ \\
& High School & $163(81.1 \%)$ \\
& College & $25(12.4 \%)$ \\
\hline Occupation & Housewife & $190(94.5 \%)$ \\
& Gainfully employed at home & $10(5 \%)$ \\
& Gainfully employed outside & $1(0.5 \%)$ \\
\hline Age at marriage & $<18$ years & $8(4 \%)$ \\
& $>18$ years & $193(96 \%)$ \\
\hline Years of married life & $<1$ year & $130(64.6 \%)$ \\
& $1-5$ years & $59(29.3 \%)$ \\
& $6-10$ years & $12(15.9 \%)$ \\
\hline Parity & 1 & $146(72.6 \%)$ \\
& 2 & $51(25.4 \%)$ \\
& 3 & $2(1 \%)$ \\
& 4 & $2(1 \%)$ \\
\hline
\end{tabular}


Table. 2 Knowledge regarding breastfeeding in the study population $(\mathrm{N}=201)$

\begin{tabular}{|l|l|l|}
\hline Sl. No. & Questions Asked & $\begin{array}{l}\text { Correct answers } \\
\text { N(\%) }\end{array}$ \\
\hline 1 & What is the quantity of breast milk produced within first day? & $16(8)$ \\
\hline 2 & What should be fed to the baby as soon as it is born? & $20(10)$ \\
\hline 3 & Knowledge regarding exclusive breastfeeding & $30(14.9)$ \\
\hline 4 & $\begin{array}{l}\text { Knowledge about proper positioning and attachment of the } \\
\text { baby during breastfeeding }\end{array}$ & $31(15.4)$ \\
\hline 5 & $\begin{array}{l}\text { Knowledge regarding the wrapping of baby to the mother while } \\
\text { breastfeeding }\end{array}$ & $67(33.3)$ \\
\hline 6 & Knowledge regarding feeding colostrum to the baby & $57(28.4)$ \\
\hline
\end{tabular}

Table.3 Knowledge regarding new born care practices in the study population

\begin{tabular}{|l|l|}
\hline New born care questions & Correct answers N (\%) \\
\hline 1. When should the baby pass meconium? & $29(14.4)$ \\
\hline 2. Knowledge regarding vaccination : Hepatitis B & $76(15.4)$ \\
\hline 3. Knowledge regarding vaccination : BCG & $107(53.2)$ \\
\hline 4. When should the baby be given first bath? & $41(20.4)$ \\
\hline 5. When does the cord fall off? & $58(28.9)$ \\
\hline 6. What are the signs of infection in cord? & $69(34.3)$ \\
\hline
\end{tabular}

On interviewing the women, it was found that there was poor knowledge among the women regarding the various aspects of breastfeeding. Owing to traditional practices, many women thought it was harmful to feed colostrum to the baby. This practice was accompanied with another harmful practice, that of giving pre-lacteal feeds in the form of jaggery, honey or sugar water to the baby soon after birth. These practices are found not only in India but also in the neighbouring countries like Bangladesh, Pakistan and Nepal, quoting Hanif (2011), Joshi (2012) and Joshi (2014) et al., Also, in the present study, it was found that the women were unaware of the benefits of colostrum feeds and the harmful effects of pre-lacteal feeds in terms of immunity, growth and future development of the baby.

Disappointingly, only around $15 \%$ of the women had correct knowledge regarding positioning and attachment of the baby to the breast during breastfeeding. This has important implications with regards to development of cracked nipples and eventual cessation of breastfeeding. On further probing, it was found that a lot of women rely on the experience obtained from their mothers or relatives for the correct practice of breastfeeding once the child is born. Half of the study population (53.4\%) had adequate knowledge regarding BCG vaccination, which is given soon after the birth of the baby. However, they did not fare so well on asking questions regarding cord care, keeping the baby warm and passage of meconium. This is similar to a study done in Bangladesh, where the knowledge regarding essential newborn care practices was relatively low as found by Moran (2009). This finding is of significance, as these are evidencebased practices in reducing neonatal mortality.

It was noticed that as the parity increased, the knowledge regarding breastfeeding and newborn care practices increased in the mothers. This was expected as rural women have lower accessibility to knowledge regarding routine newborn care, as seen in the Nepal study, and they rely heavily on their past experiences and the experiences of their peers and elders. This also suggests the lack of proactive knowledge seeking when women are in the antenatal period or the lack of access to knowledge regarding breastfeeding and essential newborn care practices. Mothers and elder women in the family of the pregnant women play a very important role in educating young mothers regarding essential newborn care and the breastfeeding practices. Hence, it is the authors' opinion that mothers of the pregnant women have to be targeted for imparting knowledge regarding essential newborn care practices and breastfeeding practices along with the antenatal women. 
Thus, we can conclude that the knowledge regarding newborn care practices and breastfeeding in women from a rural area in Karnataka was poor; with a lot of scope for improvement especially regarding the misconceptions of colostrums feeding, pre-lacteal feeds, cord care and other components of essential newborn care practices.

Limitations of the study: This was a hospital based study, which could have missed out a few women in the community who would not have accessed health care.

\section{References}

Cherop, C.E., Keverenge-Ettyang, A.G., Mbagaya, G.M. 2009. Barriers to exclusive breastfeeding among infants aged 0-6 months in Eldoret municipality, Kenya. East African J. Public Health, 6(1):

Government of India. 2006. Handbook on the prohibition of child marriage Act. India.

Hanif, H.M. 2011. Trends in breastfeeding and complementary feeding practices in Pakistan, 19902007. Int. Breastfeeding J., 6(11).

Joshi, P.C., Mirak, R., Angdembe, S. 2014. Prevalence of exclusive breastfeeding and associated factors among mothers in rural Bangladesh: a crosssectional study. Int. Breastfeeding J., 9.

Joshi, S., Barakoti, B., Lamsal, S. 2012. Colostrum Feeding: Knowledge, Attitude and Practice in Pregnant Women in a Teaching Hospital in
Nepal. Web med Central Medical Education, 3(8): doi: 10.9754/journal.wmc.003601.

Madhu, K., Chowdary, S., Masthi, R. 2009. Breast feeding practices and newborn care in rural areas: A descriptive cross-sectional study. Indian $J$. Community Med., 34(3).

Ministry of Health and Family Welfare. 2017. National Family Health Suvey-4. http://rchiips.org/NFHS/factsheet_NFHS-4.shtml

Moran, C.A. 2009. Newborn care practices among slum dwellers in Dhaka, Bangladesh: a quantitative and qualitative exploratory study. BMC Pregnancy and Childbirth, 9(54):

Nkala, T.E., Msuya, S.E. 2011. Prevalence and predictors of exclusive breastfeeding among women in Kigoma region, Western Tanzania: a community based cross-sectional study, Int. Breastfeeding J., 6(17).

Thurman, S.E., Allen, P.J. 2008. Integrating lactation consultants into primary health care services: are lactation consultants affecting breastfeeding success? Pediatric Nursing, 34(5).

World Health Organization. 2017. Infant Mortality Rate. http://www.who.int/gho/child_health/mortality/neon atal_infant_text/en/

World Health Organization. Guidelines on maternal, newborn, child and adolescent health approved by the WHO guidelines review committee. http://www.who.int/maternal_child_adolescent/docu ments/guidelines-recommendations-newbornhealth.pdf.

\section{How to cite this article:}

Rashmi, P.K., Avita Rose Johnson, Sangeetha Zacharias, Dayana, Rincy and Twinkle Agrawal. 2017. Assessment of Knowledge Regarding Essential New Born Care among Women Availing Antenatal Care Services at a Rural Maternity Hospital in Southern Karnataka. Int.J.Curr.Res.Aca.Rev. 5(4), 12-16.

doi: https://doi.org/10.20546/ijcrar.2017.504.003 